Eur J Clin Chem Clin Biochem

$1995 ; 33: 865-868$

() 1995 Walter de Gruyter \& Co.

Berlin $\cdot$ New York

\title{
Biochemical and Enzymological Study of Lactate Dehydrogenase Isoenzymes from Commercial Quality Control Sera and Several Animal Tissue Sources
}

\author{
By Kiyoh Tanishima, Sun Xian Gao ${ }^{1}$ ), Rie Yamamoto and Hisayo Yoshida \\ Department of Clinical Laboratory Sciences, School of Allied Medical Professions, Kanazawa University, \\ Kanazawa, Ishikawa, Japan
}

(Received May 5/August 3, 1995)

Summary: We assayed the isoenzymes of lactate dehydrogenase (EC 1.1.1.27) in commercial quality control sera and several animal tissue extracts, using electrophoresis. We compared the $K_{\mathrm{m}}$ values and activation energies of the isoenzymes, in order to find suitable animal tissue sources with a similar isoenzyme profile to that of human serum lactate dehydrogenase.

Some of the control sera contained only one isoenzyme fraction corresponding to porcine heart isoenzyme-1 or chicken heart isoenzyme-1, which showed essentially no changes of enzyme acitivity as a function of pyruvate substrate concentration. Other control sera, which contained isoenzymes from human red cell haemolysates, or from animal tissue extracts with a human serum matrix, showed significant changes of enzyme activity as a function of substrate concentration, and showed different $K_{\mathrm{m}}$ values and activation energies from those of human serum. Of the serum and tissue samples from several animal sources, rat heart and kidney extracts showed the greatest similarity to human serum, with respect to the electrophoretic pattern and the $K_{\mathrm{m}}, \mathrm{pH}$ optimum and activation energy of lactate dehydrogenase isoenzymes.

\section{Introduction}

Enzyme survey material is an important means of evaluating the internal consistency of results. Most laboratories use commercial reference materials for assessing enzyme activity. Since the need for stable enzyme preparations with known activity in analysis was pointed out by Moss in 1971 (1), however, the assessment of enzyme activity in control survey programmes has shown that existing commercial materials are deficient in commutability characteristics; this is because enzyme activity measurements are complicated by the multiplicity of analytical procedures, reporting units, intrinsic isoenzyme variability and matrix effects (2-7). In the case of lactate dehydrogenase ${ }^{2}$ ), a great variety of isoenzymes has

\footnotetext{
1) Present Address: Department of Pathophysiology, Cancer Research Institute, Kanazawa University, 13-1 Takaramachi, Kanazawa, Ishikawa 920, Japan

2) Enzyme

Lactate dehydrogenase ( $L$-lactate : $\mathrm{NAD}^{+}$oxidoreductase, EC 1.1.1.27)
}

been observed in commercially available reference materials. Lack of commutability for this enzyme in commercial quality control sera appears to be the result of this variety of isoenzymes. Standard reference materials with similar isoenzyme constituents to those of human serum and with consistent values are necessary for the assessment of serum lactate dehydrogenase activities in routine laboratories.

We examined the biochemical and enzymological properties of lactate dehydrogenase isoenzymes from several animal tissues, as well as commercial quality control sera, to find suitable animal tissue sources with isoenzyme profiles similar to that of human serum.

\section{Materials and Methods}

Serum and tissue extracts

Normal human serum samples were obtained from healthy student volunteers in our University after obtaining informed consent. Bo- 
vine, porcine and chicken serum samples, as well as liver, heart and muscle specimens were obtained from the slaughterhouse of our city. Rabbit, rat, guinea pig and mouse serum, as well as tissue samples were obtained through the Institute of Experimental Animals of our University under the guidelines of the Institutional Review Board. Fresh fish (Sardina) was purchased at a market. The tissue and serum specimens weres stored at $-80^{\circ} \mathrm{C}$ until use for enzyme extraction.

\section{Extraction procedure for tissue}

The tissues were homogenized in Tris $\mathrm{HCl}$ buffer $(20 \mathrm{mmol} / \mathrm{l}, \mathrm{pH}$ 7.4) in an ice bath, then centrifuged at $1000 \mathrm{~g}$ for $15 \mathrm{~min}$. The supernatants were centrifuged at $10000 \mathrm{~g}$ for $30 \mathrm{~min}$, then stored in aliquots at $-80^{\circ} \mathrm{C}$ for enzyme activity measurement and isoenzyme assay. Lactate dehydrogenase isoenzymes from the tissue extracts were further fractionated in a stepwise manner on QAESephadex A-50 as described by Hsu et al. (8).

\section{Electrophoresis of lactate dehydrogenase isoenzymes}

Lactate dehydrogenase isoenzymes were separated electrophoretically on a buffered agarose gel at $\mathrm{pH} 8.2$ using a commercially available kit (Beckman Paragon LD, Beckman Instruments Inc., La Brea, CA). After electrophoresis the isoenzymes were detected by measuring the pioduction of nitroblue formazan dye, according to the instructions provided with the same kit.

\section{Measurement of lactate dehydrogenase activity}

Lactate dehydrogenase activity was measured with the Monarch Chemistry System (Instrumentation Laboratory Inc., Lexington, MA) using a commercial kit with pyruvate as substrate (LDH-HA Test WAKO, Wako Pure Chemical Industries Ltd., Osaka, Japan). We also performed a spectrophotometric rate assay of the enzyme activity using a Hitachi 150-20 Spectrophotometer (Hitachi Ltd., Tokyo, Japan), and the results were used to determine $K_{\mathrm{m}}$ ([S]/v plot) and activation energy. The reducing of pyruvate was monitored by following the NADH oxidation at $340 \mathrm{~nm}$ and $30^{\circ} \mathrm{C}$. The assay mixture consisted of $50 \mu \mathrm{l}$ of enzyme, $2.0 \mathrm{ml}$ of sodium phosphate buffer $(67 \mathrm{mmol} / \mathrm{l}, \mathrm{pH} 7.4$ ) containing $0.22 \mathrm{mmol}$ of $\mathrm{NADH}$ per litre and $100 \mu \mathrm{l}$ of various concentrations of pyruvate (9). All chemicals and reagents were of analytical grade or equivalent.

\section{Commercial quality control sera}

We used 13 commercially available quality control sera:

A) EXA Liquid 5 (Sankoh Laboratory Service Center, Tokyo, Japan),

B) Decision LEVEL 1, 2 and 3 (Beckman Instruments, Inc., La Brea, CA),

C) Liquid Control Serum WAKO (Wako Pure Chemical Industries, Ltd., Osaka, Japan),

D) Moni-Trol (Baxter Healthcare Co., Dade Div., Miami, FL),

E) Nescol-X and -XA (Kaketsuken Lab., Kumamoto, Japan),

F) Q-PAK (Cooper Biomedical Inc., Malvern, PA),

G) TWIN-CONSERA (Nissui Pharmaceutical Co. Ltd., Tokyo, Japan),

H) Precinorm E and Precipath E (Boehringer Mannheim GmbH, Mannheim, Germany),

I) Enzyme Reference WAKO (Wako Pure Chemical Industries, Ltd., Osaka, Japan),
J) Seraclea-HE (Kaketsuken Lab., Kumamoto, Japan),

K) 3 in 1 Control (Ciba Corning Diagnostics Co., Palo Alto, CA),

L) SUITROL (Nissui Pharmaceutical Co. Ltd., Tokyo, Japan), and

M) Liquid Reference (Ciba Corning Diagnostics Co., Irvine, CA).

$\cdot 1$

\section{Results}

Electrophoretic profile of isoenzymes in quality control sera

We compared the electrophoretic patterns of lactate dehydrogenase isoenzymes in several commercially available quality control sera with those in sera from humans and animals. The results showed that some quality control sera (A, B, C, D, E, F and G) contained additional isoenzyme fractions corresponding to those of some animal sera in the human serum matrix. Control serum $\mathrm{H}$ contains only one isoenzyme fraction which is different from any of the 5 isoenzymes in human serum. Control sera $I, J, K, L$ and $M$ migrated with the same profile as that of human serum.

To identify the properties of the specific isoenzyme fractions in quality control sera $\mathrm{A}-\mathrm{H}$, which differed from the 5 lactate dehydrogenase isoenzymes in human serum, we compared their electrophoretic profiles with those of enzymes from several animal tissue sources. Control serum A, B, C and D contained the 5 isoenzyme fractions similar to those of the normal human serum lactate dehydrogenase, as well as an additional fraction corresponding to the chicken isoenzyme-1, but not to fish isoenzyme fractions. The fractions in control serum E-I and G-I (normal activity range) are of those in normal human serum, but control serum E-II and G-II (pathological activity range) contained some fractions corresponding to porcine isoenzyme- 1 and -5 fractions on the human serum matrix. The control serum F (I and II) contained some fractions corresponding to those of porcine isoenzyme-1, normal human serum and other unindentified fractions. The control serum H-I contains a fraction corresponding to the porcine isoenzyme-1 on the human serum matrix, but H-II consisted of only the porcine isoenzyme-1 fraction.

\section{$K_{\mathrm{m}}$ value and activation energy}

For further studies on the properties of the specific isoenzyme fractions in control sera, we compared their $K_{\mathrm{m}}$ values and activation energies with those of animal tissue lactate dehydrogenase isoenzymes (tab. 1). These values of the specific isoenzyme fractions in control serum $B$ and $D$ are similar to those of isoenzyme- 1 in chicken heart extract, and the values of isoenzyme fraction in control serum $\mathrm{H}$ are essentially the same as those 
of isoenzyme-1 in porcine heart extract. In control serum E, which contains the major cathodal fraction and other minor fractions, the values were close to those of isoenzyme-3 in chicken muscle extract. The $K_{\mathrm{m}}$ values and activation energies of the isoenzymes in control sera I and $\mathrm{J}$ (which contain human erythrocyte haemolysate, according to the manufacturer) display $K_{\mathrm{m}}$ values and activation energies similar to those of the isoenzymes of human sera. In addition, it is evident that $K_{\mathrm{m}}$ values and activation energies of the enzyme in rat kidney and heart extracts are very close to those of human serum.

\section{Studies on rat tissue extracts}

We studied the relationship between velocity and substrate concentration, as well as the effect of $\mathrm{pH}$ on enzyme activity for lactate dehydrogenase from rat tissue extracts, and compared the results with those from human serum.

Optimum values of $\mathrm{pH} 7.57$ for rat heart extract, $\mathrm{pH}$ 7.45 for kidney extract and $\mathrm{pH} 7.43$ for human serum were found, using the $95 \%$ maximum activity horizontal line on the pH-enzyme activity curves (fig. 1). In the plots of velocity vs substrate concentration $([\mathrm{S}] / v$ plot)

Tab. 1 Activation energies and $K_{\mathrm{m}}$ values of lactate dehydrogenase in human blood sources, quality control sera and animal tissue sources

\begin{tabular}{lcl}
\hline & $\begin{array}{l}K_{\mathrm{m}} \text { value } \\
(\mu \mathrm{mol} / \mathrm{l})\end{array}$ & $\begin{array}{l}\text { Activation energy } \\
(\mathrm{KJ} / \mathrm{mol})\end{array}$ \\
\hline Human serum & 53 & 22.8 \\
isoenzyme 1 & 56 & 36.9 \\
isoenzyme 5 & 286 & 40.9 \\
erythrocytes & 81 & 33.3 \\
& & \\
Quality control sera & & \\
B & 90 & 21.6 \\
D (pathological) & 84 & 23.9 \\
E (pathological) & 170 & 25.9 \\
H (normal) & 172 & 17.4 \\
I & 88 & 27.7 \\
J (normal) & 56 & 35.6 \\
J (pathological) & 81 & 25.4 \\
& & \\
Pig & & \\
heart isoenzyme 1 & 167 & 15.6 \\
liver isoenzyme 5 & 238 & 38.2 \\
Chicken & & \\
heart isoenzyme 1 & 88 & 28.2 \\
liver isoenzyme 2 & 95 & 27.0 \\
muscle isoenzyme 3 & 104 & 25.6 \\
Rat & & \\
whole heart extract & 75 & 28.4 \\
whole kidney extract & 61 & 2.4 \\
whole muscle extract & 294 & - \\
whole liver extract & 175 & \\
\hline
\end{tabular}

for human serum and for control sera A, D and E, enzyme activities were maximal at a substrate concentration of $0.6 \mathrm{mmol} / 1$ pyruvate and were decreased at higher concentrations; the plots for the other control sera (C, F, G, I, J, K, L and M) revealed the same effects. Rat muscle, heart and kidney extracts showed the same tendency as human serum in the $[\mathrm{S}] / v$ plot. Rat liver extract, which contained mainly one major isoenzyme fraction, showed a constant velocity for the enzyme catalysed reaction in the range of 0.6 to $2.0 \mathrm{mmol} / \mathrm{l} \mathrm{pyr-}$ uvate $([\mathrm{S}] / v$ plots for control serum $\mathrm{B}$ and $\mathrm{H})$.

\section{Discussion}

Stable enzyme reference materials with a consistent activity value are required as internal standards and for control survey programmes $(6,10-14)$. Most of the commercially available control sera studied here contained various lactate dehydrogenase isoenzymes from animal tissue sources (e.g. porcine, chicken) with a human serum matrix. The enzyme source is occasionally indicated by the manufacturer, but usually it is unknown.

In determining the lactate dehydrogenase activity of quality control materials, such as the internal or external standard, different results are often observed according to the methodology or reaction conditions. Problems therefore arise when the enzyme activity of the same control serum is measured with different commercial assay kits. This is due to differences in the isoenzyme characteristics of each control serum (15). Buhl et al. (10) have reported a marked improvement in the accuracy of virtually all methods used to determine enzyme

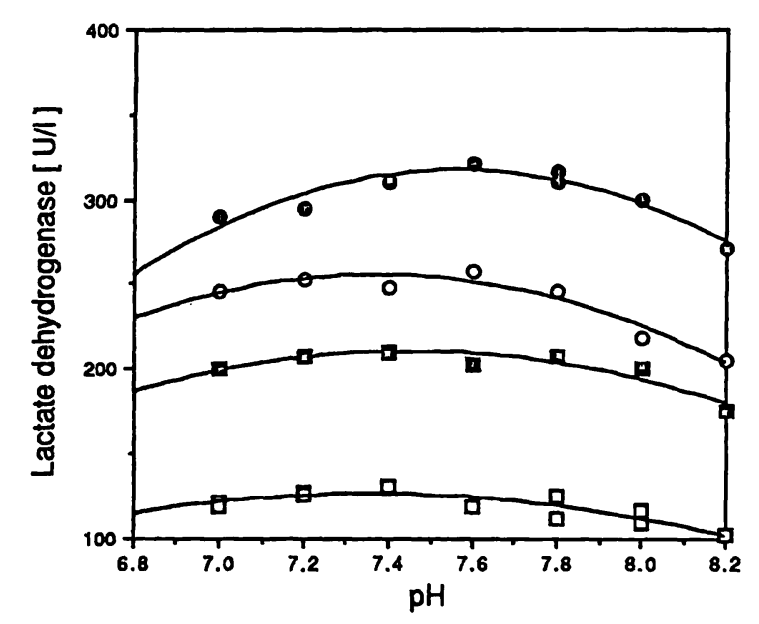

Fig. 1 Lactate dehydrogenase activities of normal human serum and rat tissue extracts at different hydrogen ion concentrations, using pyruvate as substrate in Tris $\mathrm{HCl}$ buffer $(10 \mathrm{mmol} / \mathrm{l})$.

- Rat heart extract

O Human serum 1

- Rat kidney extract

$\square$ Human serum 2 
activities by using a highly purified human lactate dehydrogenase preparation, suspended in the serum matrix during proficiency testing. When we used control sera $\mathrm{B}$ and $\mathrm{H}$ in this study, which contained a single isoenzyme fraction from chicken and porcine tissue sources, relatively consistent values were obtained over the wide range of substrate concentrations. A similar consistent value was observed in each $[\mathrm{S}] / v$ plot for rat serum, rat liver extract and diluted chicken serum. However, with regard to their use as human serum type reference material, the isoenzyme profiles of these specimens are not similar to those of human serum. On the other hand, control serum I and J contain erythrocyte haemolysates of human origin and have a similar electrophoretic profile to that of normal human serum, but the enzymic characteristics such as activation energy and substrate binding capacity are different. This seems to be due to the fact that human adult blood erythrocytes represent a range of cell populations of different ages. Krijnen et al. (16) investigated lactate dehydrogenase isoenzymes prepared from human erythrocytes and the placenta, and

\section{References}

1. Moss DW. Accuracy, precision and quality control of enzyme assays. J Clin Pathol 1971; 24 Suppl 4:22-30.

2. Miller WG, Rhodes DJ, Moore CJ. A calibration protocol for serum-based secondary standards. Clin Chem 1982; 28:2195-200.

3. Bowers GN Jr, McComb RB. A unifying reference system for clinical enzymology: aspartate aminotransferase and the international clinical enzyme scale. Clin Chem 1984; 30:1128-36.

4. Miller WG, Crane PD, Cryer C. Interlaboratory standardization of enzyme results: the Richmond project. Clin Chem 1986; 32:1525-31.

5. Kairisto V, Virtanen A, Uusipaikka E, Voipio-Pulkki LM, Näntö V, Peltola $O$, et al. Method for determining reference changes from patients' serial data: example of cardiac enzymes. Clin Chem 1993; 39:2298-304.

6. Rej R. Accurate enzyme activity measurements. Two decades of development in the commutability of enzyme quality control materials. Arch Pathol Lab Med 1993; 117:352-64.

7. Rej R. Proficiency testing, matrix effects, and method evaluation [editorial]. Clin Chem 1994; 40:345-6.

8. Hsu MY, Kohler MM, Barolia L, Bondar RJL. Separation of five isoenzymes of serum lactate dehydrogenase by discontinuous gradient elution from a miniature ion-exchange. Clin Chem 1979; 25:1453-8.

9. Association of Clinical Biochemists Working Party Recommendations. Proposed methods for determination of some enzymes in blood serum. Assoc Clin Biochem News Sheet 1980; Feb:16S.

10. Buhl SN, Copeland WH, Fasce CF Jr, Kowalski P, Richards $\mathrm{AH}$, Vanderlinde RE. Proficiency testing: purification of lactate dehydrogenase 1 and results of its use as a reference material in the New York State program. Clin Chem 1977; 23:1000-11.

11. Duncan PH, McKneally SS, Macneil ML, Fast DM, Bayse DD. Development of a reference material for alkaline phosphatase. Clin Chem 1984; 30:93-7. found that all preparations were heterogeneous both with respect to the protein and isoenzyme content.

Since the lactate dehydrogenase isoenzymes of rat heart and kidney extracts resemble those of human serum, they would be satisfactory reference materials for use as lactate dehydrogenase activity calibrators. They could be used also as reference materials for calibrating electrophoretic assays of lactate dehydrogenase isoenzymes as described by Smith et al. $(17,18)$. Further investigations must be carried out on the preparation of materials suitable for use as interlaboratory calibration materials and on the demonstration of their commutability properties among a representative number of common laboratory methods.

\section{Acknowledgements}

We are grateful to Prof. J. Hayakawa of the Institute of Experimental Animals of Kanazawa University and to Dr. S. Okabe, Veterinarian of the Kanazawa City Slaughterhouse, for their providing animal tissue specimens.
12. Moss DW, Schiele F, Siest G, Colinet E. Reference materials for clinical enzymology: the work of the community bureau of reference of the European community. Clin Chem 1986; 32:556-8.

13. Koedam JC, Steentjes GM, Buitenhuis S, Schmidt E, Klauke $R$. Production and certification of secondary enzyme reference materials (ERMs). Part 1: preparation of the sera and some of their properties. Clin Chem 1986; 32:1901-5.

14. Bowers GN Jr, McComb RB, Syed D, Edwards GC, Edwards J, Paule RC, et al. Primary human aspartate aminotransferase reference material. The catalytic acitivity concentration of AST in RM 8430 as measured by the IFCC reference method for AST in 10 enzyme standardization laboratories. Clin Chem 1988; 34:450-9.

15. Gay RJ, McComb RB, Bowers GN Jr. Optimum reaction conditions for human lactate dehydrogenase activity. Clin Chem 1968; 14:740-53.

16. Krijnen PMW, Leung FY, Henderson AR. Commercial preparations of human lactate dehydrogenase isoenzymes are not homogeneous [letter]. Clin Chem 1987; 33:1289.

17. Smith DA, Moses GC, Henderson AR. Use of purified lyophilized human lactate dehydrogenase isoenzymes in a study of the measurement of lactate dehydrogenase activity. Clin Chem $1986 ; 32: 758-62$.

18. Smith DA, Moses GC, Henderson AR. Use of purified lyophilized human lactate dehydrogenase isoenzyme 5 in a study of measuring lactate dehydrogenase activity. Clin Chem 1989; 35:1174-6.

Kiyoh Tanishima

Department of Clinical Laboratory Sciences

School of Allied Medical Professions

Kanazawa University

5-11-80 Kodatsuno

Kanazawa

Ishikawa 920

Japan 